\title{
A CASE OF SERTOLI-LEYDIG CELL TUMOR OF OVARY IN YOUNG WOMAN: A RARE DISEASE
}

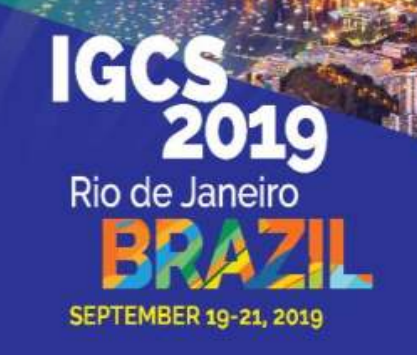

G. Resende ${ }^{1}$, B. Ruiz² ${ }^{2}$ V. Sanz ${ }^{3}$, Y.L. Viana ${ }^{4}$, E. Azevedo ${ }^{5}$.

1Foundation Center of Oncology Control - FCecon, Department of Clinical Oncology, Manaus, Brazil.

2University Nilton Lins - UNL, Faculty of Medicine, Manaus, Brazil.

${ }^{3}$ Foundation Center of Oncology Control - FCecon, Department of Surgical Oncology, Manaus, Brazil.

4 University of Technology of Amazonas - UEA, Faculty of Medicine, Manaus, Brazil.

${ }_{5}^{5}$ Foundation Center of Oncology Control - FCecon, Department of Pathology, Manaus, Brazil.

\section{OBJECTIVES}

We reported a Sertoli-Leydig cell tumor with symptoms of hyperandrogenism.

\section{METHODS}

Sertoli-Leydig cell tumor (SLCT) also called androblastoma represents less than $0,5 \%$ of all primary ovarian tumor. The majority of SLCTs are unilateral and confined to the ovaries. It's more common in young women between the age of 25 and 35 . In approximately $90 \%$ of the cases are diagnosed as Stage IA.

\section{RESULTS}

We reported a case of SLCT in a 17-year-old female who was presented at emergency room with acute abdominal pain caused by an ovarian torsion. She underwent an emergency laparotomy with confirmed finding of an ovarian tumor without disease at peritoneal cavity. Histopathological examination showed a well encapsulated gray colored solid mass with smooth external surface measuring $16.0 \times 14.5 \times 11.0 \mathrm{~cm}$. The patient did not receive any adjuvant treatment. After ten months, she presented a pelvic peritoneal recurrence associated with symptoms of hyperandrogenism including hirsutism, deepening of the voice as well amenorrhea. Optimal oncologic cytoreduction surgery was performed. Histopathological exam confirmed Sertoli- Leydig tumor. Immunohistochemical revealed positive for inhibin alpha, FOXL2 and calretinin. The patient received six cycles of carboplatin and paclitaxel chemotherapy regimen. After treatment, the symptoms of hyperandrogenism disappeared. In the moment, the patient has been in a follow-up without any evidence of disease.

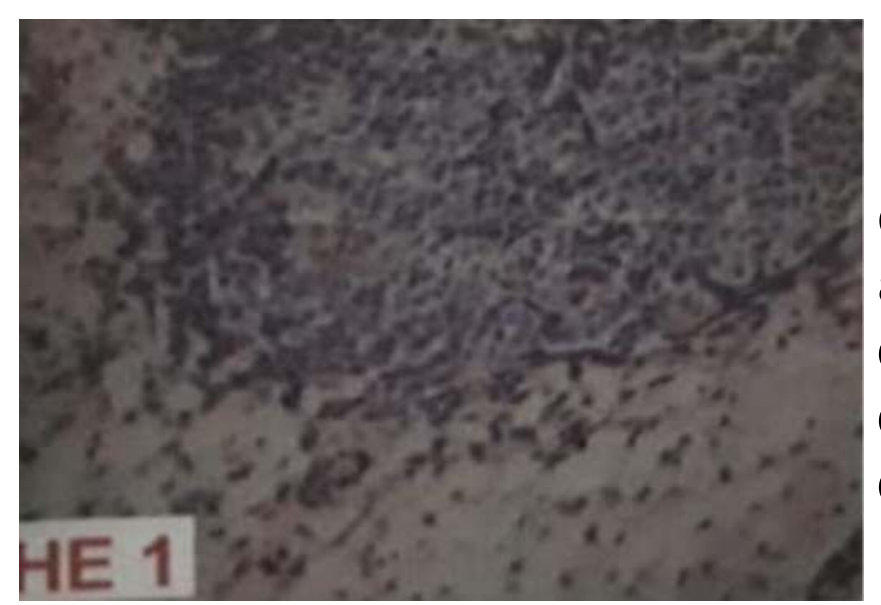

Figure 1 - Solid blocks of epithelioid cells exhibited a discreet atypia and pale cytoplasm without specific characters of granulosa cells $(H$ and $E, \times 10)$.

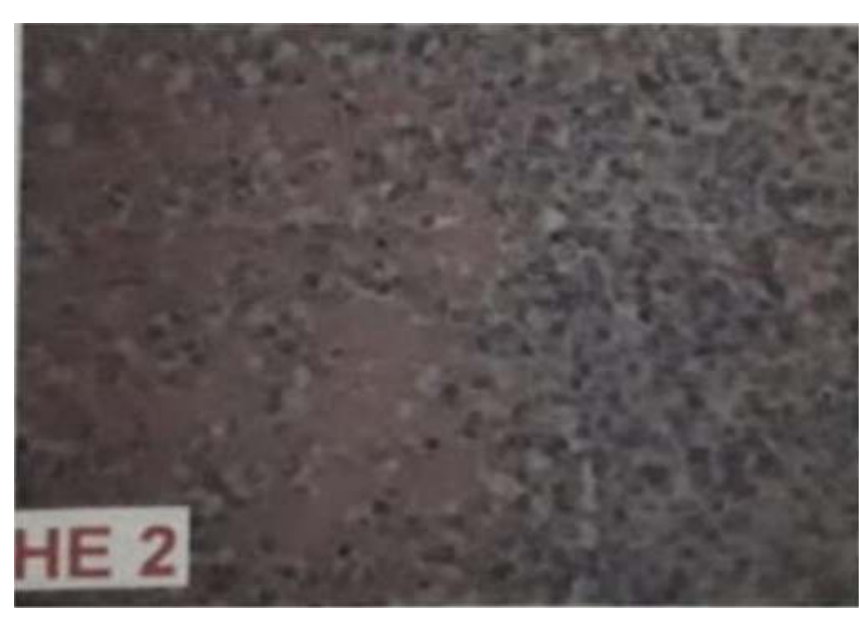

Figure 2 - A few epithelioid cells with round nuclei and eosinophilic cytoplasm (H and $\mathrm{E}, \times 10)$

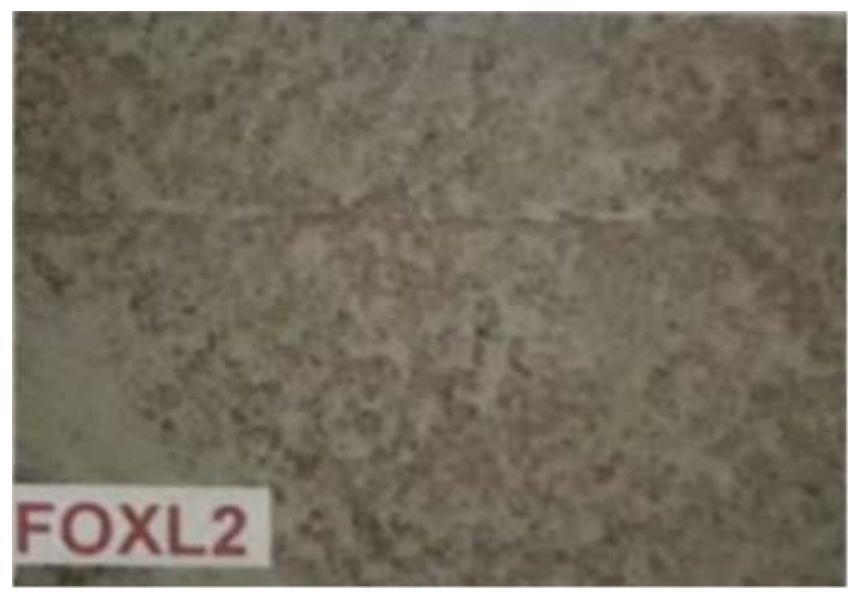

Figure $3 \quad-$ Overexpression of FOXL2 in Sertoli-Leydig cell tumor detected by immunohistochemical stain.

\section{CONCLUSION}

There is not consensus about the best treatment options. Surgery is still the standard treatment of primary and resectable cases. After recurrence, chemotherapy with platinum and taxares agents are useful in clinical practice.

\section{REFERENCES}

1. Gómez-Peñaloza C, Cañavera-Constantino A, AristiUrista G. Bilateral, metachronic ovarian Sertoli-Leydig cell tumour in an 11-year-old patient: A case report. Rev Médica del Hosp Gen México. 2018;81(3):139-145. doi:10.1016/j.hgmx.2017.03.008.

2. Kataria SP, Mishra K, Dev G, Tandon R. Sertoli-Leydig cell tumor of ovary with heterologous element: A case report. Indian J Pathol Microbiol. 2005;48(4):493-495.

3. Kurman RJ, Ellenson LH, Ronnett BM. Blaustein's Pathology of the Female Genital tract ,6th ed. Springer, 2011.

4. Crum CP, Nucci MR,Howitt BE, Granter SR,ParastMM, Boyd TK. Diagnostic Gynecologic and Obstetric Pathology. 3rd ed. Elsevier Saunders, 2018. 